Relato de Experiência

\title{
A construção do "eu" professora de Libras
}

\author{
The construction of the "I" Libras teacher
}

\author{
La construcción del "yo" maestro Libras
}

\section{Geisiele Cavalcante de Sousa', Marilene Calderaro da Silva Munguba", Keren Rachel Santos Clark"II}

\begin{abstract}
'Discente do Curso de Letras-Libras na Universidade Federal do Ceará.
"Doutora em Ciências da Saúde pela Universidade Federal do Rio Grande do Norte - UFRN (2008) e Docente Adjunta A/DE da Universidade Federal do Ceará - UFC, lotada no Centro de Humanidades, no Departamento de Letras Libras e Estudos Surdos - DELLES (2018). "'No âmbito do Programa Núcleo Rondon na UFC, tem se dedicado em palestrar para adolescentes e jovens sobre formação pessoal e planejamento de carreira. É também Coordenadora do Projeto de Extensão Clube de Libras UFC, o qual visa difundir o conhecimento e a prática da Língua Brasileira de Sinais (Libras); e gestora voluntária dos sites Fala Sapiens (falasapiens.com) e Find Sapiens (findsapiens. com), os quais abordam temáticas variadas de amplo interesse.
\end{abstract}

\section{RESUMO}

A descoberta de uma identidade profissional é uma experiência muito singular na vida de qualquer pessoa. Por vezes, é um processo que se inicia despretensioso, vai se fortalecendo com alguns episódios e culmina com uma constatação marcante. Assim se deu a construção da identidade "professora de Libras" na autora do presente relato. Seu ingresso em um projeto de extensão focado na difusão de Libras e a experiência de lecionar esta língua para duas turmas de alunos iniciantes definiram a certeza da identificação com esta atividade. E mais ainda: a convicção de como Língua Brasileira de Sinais precisa ser mais amplamente divulgada.

Palavras-chave: Ensino de Libras. Difusão de Libras. Conhecimentos sobre a Comunidade Surda. Extensão.

\section{ABSTRACT}

The discovery of a professional identity is a very unique experience in anyone's life. Sometimes, it is a process that starts unpretentious, gets stronger with some episodes and culminates with a remarkable finding. Thus, the construction of the identity "professor of Libras" took place in the author of the present report. Her entry into an extension project focused on the spread of Libras and the experience of teaching this language to two groups of beginning students defined the certainty of identification with this activity. And even more: the conviction of how Brazilian Sign Language needs to be more widely disseminated. 
Keywords: Libras Teaching. Diffusion of Pounds. Knowledge about the Deaf Community. Extension.

\section{Resumen}

El resumen debe presentar, de forma obligatoria y clara y concisa, el objetivo central del artículo, basado en la teoría que he orientado o estudiado, como sus principales conceptos, una descripción básica de la metodología y los principales resultados obtenidos. El texto debe ser redirigido en un solo párrafo, justificado, en fuente 12, casilla incorrecta, entre líneas simples y no más de 10 líneas.

Palabras clave: Enseñanza de Libras. Difusión de Libras. Conocimiento sobre la comunidad sorda. Extensión.

\section{INTRODUÇÃO}

"O trabalho mais difícil é descobrir sua verdadeira paixão. Depois, deixará de ser trabalho." Rodrigo Chung, em Tua Carreira (2020)

Para falar um pouco da minha experiência e construção de uma professora dentro de mim, é importante resgatar o que me motivou a escolher a graduação em Letras Libras. Fazia 2 anos que eu estudava para passar em Psicologia, e como a nota de corte é bem alta, eu precisava me esforçar muito. Na época, eu cursava o preparatório para o Enem do IFCE e, um dia, vi em uma das telas de informações do campus que seria ofertado o Curso Básico de Libras. Sempre tive curiosidade em saber o que era Libras e aprender os sinais pois minha noção a respeito era muito vaga. Então, como gosto eu mesma de obter novos aprendizados, ao mesmo tempo que incentivo quem está ao meu redor no mesmo rumo, estimulei todos os meus colegas a se inscrevem junto comigo para o curso. $O$ irônico foi o resultado: todos os meus colegas passaram no curso e apenas eu não consegui entrar. Isso me deixou triste a um nível de pensar: "se apenas eu tivesse me inscrito, talvez eu tivesse mais chance de ingressar no curso". Mas este raciocínio passou logo, pois eu sabia que como todo curso, em algum momento, alguém iria desistir eu pediria ao professor para deixar que eu assumisse a vacância. Minha percepção estava correta e consegui entrar no decorrer do curso. Foi uma bela descoberta! 
Cada aula me deixava extasiada, e eu me esforçava pra aprender e amava aprender tudo aquilo. Foi assim que eu conheci a Libras como língua de estrutura e características próprias. Uma língua que representava uma comunidade com cultura própria, entre outras características singulares, das quais eram desconhecidas por me até o momento. Ter a oportunidade de aprender o que a Libras é, me abriu os horizontes para pensar em novas possibilidades de escolha na minha vida acadêmica, que logo se iniciaria.

O que mais contribuiu para que eu trocasse o desejo de cursar Psicologia para ingressar na Graduação de Letras Libras foi conhecer a luta da comunidade surda pelo reconhecimento da sua língua e pela acessibilidade, sabendo também que essas pessoas tiveram uma história longa e marcada pelo sofrimento e suas conquistas são tão recentes, e isso me incentivou a mergulhar de cabeça e adquirir mais conhecimento a respeito. Conhecer de perto a comunidade surda me fez querer fazer parte dela. Foi questão de meses (apenas a duração do curso) até eu desistir de Psicologia e decidir que eu faria Letras Libras na UFC, já que eu também não tinha a menor condição de pagar uma faculdade particular.

Esperei até que o edital fosse lançado, como incentivadora que sou, como mencionei a cima, arrastei comigo uma amiga de infância para se inscrever no curso comigo, e adivinhem? Não passei! Havia apenas 3 vagas na minha categoria e eu fiquei em $4^{\circ}$ lugar. Esperei que saísse a lista de espera e eu era a primeira. Estava torcendo para que houvesse alguma desistência, afinal eu era a próxima da lista. Isso aconteceu, passamos as duas na lista de espera, e eu enfim consegui entrar no curso. Nunca sai de casa tão feliz em pegar 2 ônibus para estudar. Afinal me deparei realizando um sonho, que precisou de muito suor e esforço para que eu chegasse até ali.

\section{O PROJETO EXTENSIONISTA DE DIFUSÃO DE LIBRAS}

No segundo semestre começaram as ofertas de bolsas e eu, claro, fui participar de uma entrevista para entrar como bolsista de um Projeto extensionista que visa difundir a Língua Brasileira de Sinais (LIBRAS). 
O projeto de extensão conta com uma equipe multidisciplinar, tendo além de docentes do curso de Letras Libras, profissionais da área da educação e da administração. Há também uma voluntária externa e, à época da seleção para bolsista, também havia vagas para voluntários, ouvintes e surdos.

Fiquei encantada com a proposta do projeto, e também estimulada pela possibilidade da bolsa, que tanto é útil como provedora de ajuda financeira, como principalmente para efeito de ponto no currículo profissional.

No dia da entrevista para a bolsa eu estava tão nervosa, pois era algo que eu queria muito tanto pela experiência, que eu sabia que seria incrível e bastante aprendizado, como pelo dinheiro da bolsa que ajudaria com custos da vida acadêmica. E eu seria entrevistada em Libras, o que me deixou mais nervosa ainda, pois eu não me considerava a mais fluente entre os candidatos que estavam na entrada esperando a vez da avaliação. Todos, apesar de alguns serem ouvintes, estavam conversando naturalmente em língua de sinais e eu me senti um pouco perdida naquele momento. Mas enfim chegou a vez de eu ser a entrevistada, por não ter conseguido compreender, de forma clara, duas das perguntas feitas, eu concluí que não tinha chance de ser selecionada. Saindo da entrevista, em cada passo que eu dava até a Biblioteca, meus olhos se enchiam de lágrimas, mas eu as contive e decidi pensar que haveria outras oportunidades.

Quando saiu o resultado, nem fui averiguá-lo, pois já estava certa de que meu nome não estaria lá. Como estava enganada! Um dos meus amigos me parabenizou por ter passado e eu corri pra olhar o resultado, para ter certeza que de fato eu tinha passado. E, sim, passei e me empolguei muito para adquirir a experiência de lecionar em Libras. Mas, aconteceu que tudo precisou parar em razão da pandemia da Covid19. O projeto, então, precisou ser reformulado: ao invés de dar aulas para os servidores da UFC, como havia sido previsto, passei a treinar interessados em uma empresa que treina cuidadores de idosos e ensina primeiros socorros., ou seja, prioritariamente profissionais da saúde.

O intuito da ação extensionista desse projeto, que é uma ação vinculada ao Programa Núcleo Rondon na UFC, é difundir o aprendizado de Libras entre os servidores da universidade onde estudo e também para a sociedade cearense. A 
ideia, a princípio, era criar grupos de estudo que se reuniriam uma vez por semana. No âmbito da UFC, seria marcado um horário (cerca de 50 minutos por semana), no qual servidores e terceirizados poderiam adquirir as noções iniciais de Libras. Fora da UFC, pretendia-se criar grupos em ambientes públicos. A metodologia escolhida de ensino foi a Aprendizagem Cooperativa. A pandemia atrapalhou este planejamento, mas por meio de uma articulação que realizei junto à proprietária da empresa supracitada, foi possível iniciar aulas presenciais na empresa em questão a partir do dia 15 de outubro.

\section{A EXPERIÊNCIA COMO PROFESSORA DE LIBRAS}

Conforme já pontuado, a empresa especializa-se no treinamento de profissionais que atuam na área de saúde, e então é interessante que estes possam ter noções de Libras a fim de poderem se comunicar com deficientes auditivos.

Foram inscritas um total de 25 pessoas no curso divididas em duas turmas. Como sempre há aqueles que desistem no percurso, ao final restaram 18 alunos participantes das aulas.

Fizemos uma pesquisa com os alunos tanto para avaliar o conhecimento adquirido no curso como também para obter algumas informações importantes. Os resultados foram bem interessantes. $55,6 \%$ dos alunos têm algum conhecido surdo, mas 66,7\% teve o primeiro contato com Libras no curso. Segundo o censo de 2013 (IBGE, 2015), no Brasil, cerca de 2,2 milhões de pessoas (1,1\% da população) possuíam deficiência auditiva. Mas o censo não relata quantos destes fazem uso da língua de sinais e sabemos, apesar de não existir um censo que aponte, que muitos surdos não têm contato com sua língua assim que nasce. Casos assim ocorrem quando um surdo nasce em uma família de ouvintes, e como em muitos casos esta família não conhece nada da língua de sinais (e até não acha importante conhecer), a família segue criando o filho surdo de forma oralizada. Alguns, sem perceber, desrespeita o membro familiar surdo por ser ignorante no assunto e/ou simplesmente por não se interessar. Fazendo que o sujeito surdo esteja no meio ouviste se reconhecendo e se comportando como tal. Skliar refere-se às práticas oralistas como fazendo parte de uma ideologia que denomina ouvintismo. Segundo ele, o ouvintismo 
"trata-se de um conjunto de representações dos ouvintes, a partir do qual o surdo está obrigado a olhar-se e a narrar-se como se fosse ouvinte". (SKLIAR 1998. P.15). foram mais de cem anos de práticas (desde o II Congresso Internacional de Milão, em 1880) visando a correção, a normalização do indivíduo surdo, visando o disciplinamento de seu comportamento e corpo para produzir surdos aceitáveis para a sociedade ouvinte e que se portassem como tal.

Tenho alguns amigos surdos que podem falar melhor sobre o assunto, por serem suas vivências. Alguns deles apenas obtiveram o contato com Libras e aprenderam a língua depois de seus 7, 10, 17 anos de idade. Pode parecer absurdo, mas é a realidade.

Certamente foi devido a estas questões, relacionadas ao contato tardio de alguns surdos com Libras, que mesmo tendo conhecidos surdos, meus alunos não tiveram contato com a língua de sinais antes. Uma das minhas alunas relatou, em sala, que sua vizinha tem uma filha surda, e que ela não tem contato com Libras, e que se comunica por meio de gestos e apontamentos, já que não oraliza de maneira que todos entendam. Eu mesma tive contato com um menino, na faixa etária de 7 a 8 anos, cuja mãe "achava" que não precisava que ele tivesse conhecimento de Libras.

Para Vygotsky, "a trajetória principal do desenvolvimento psicológico da criança é uma trajetória de progressiva individualização, ou seja, é um processo que se origina nas relações sociais, interpessoais e se transforma em individual, intrapessoal." (VYGOTSKY, 1989). No caso dos surdos, é essencial que a criança tenha contato com Libras desde o início da sua aquisição linguística, a fim de que esse processo de desenvolvimento não seja tardio. As relações sociais e interpessoais pressupõem indivíduos que se comuniquem na mesma língua. Acontece, como já citado alguns exemplos, que muitos surdos, por não ter uma família que entenda importância e/ou não conheça a língua de sinais, acabam tendo o contato tardio com a sua língua e isso acaba prejudicando o seu desenvolvimento progressivo de individualização e suas relações interpessoais.

Quanto menos pessoas souberem acerca da importância da língua de sinais para a sociedade em geral, mais surdos crescerão sem o contato imediato com a língua. Ao contrário, esse contato será provavelmente tardio, assim como tem ocorrido 
atualmente. Tanto surdos quanto ouvintes precisam conhecer e reconhecer a importância da língua de sinais. É necessário que a sociedade se sensibilize, como um todo, por esta importante causa.

Sabendo da importância de fazer com que as pessoas tenham acesso a essas informações supracitadas, é claro que no curso introdutório de Libras, não se ensina apenas os sinais em Libras, mas também as implicações da Libras e da comunidade surda, para que os alunos conheçam e compreendam que a língua de sinais é de fato importante para a acessibilidade e para qualidade de vida dessas pessoas. Na nossa pesquisa foi feita a seguinte pergunta: "O aprendizado de Libras mudou algo na sua visão depois de fazer o Curso Introdutório de Libras?" 99\% das pessoas responderam que sim. Alguns comentários são apresentados a seguir:

\footnotetext{
"Sim, agregou novos conhecimentos e ampliou a minha visão a respeito da língua [...]" "Sim, minha visão geral sobre a comunidade surda."

"[...] O Curso ajuda a aprendermos mais sobre a cultura surda além da Libras."

"Sim, pois vemos os surdos de outra maneira."

"Sim, a importância de conseguir uma comunicação de qualidade ao prestar um serviço."

"Sim, para promover a inclusão."
}

A partir destas respostas, podemos enxergar que um simples curso introdutório de Libras é capaz de promover um pequeno despertar, no sentido de mudar a visão de alguns a respeito do sujeito surdo, sua língua, cultura e comunidade.

Pude ver que a proposta deste curso oportunizou conhecimentos válidos na vida dos participantes. Coerente com minhas motivações para ingressar em Letras Libras, o ensino de Libras representa para mim não só o compartilhar de uma nova língua, mas também a sensibilização de ouvintes para entenderem mais sobre a comunidade surda e suas lutas.

Esta experiência como professora de Libras é deveras gratificante! Recebo constantemente dos alunos olhares e variadas demonstrações de gratidão, em especial pelo incentivo de não desistir deste conhecimento e tornaram-se, assim como eu, multiplicadores e incentivadores do aprendizado de Libras. É mais que necessário que a difusão de Libras seja ampliada. 
De acordo com a pesquisa realizada, $100 \%$ dos alunos acredita que aprender Libras não é somente relevante, como também repercutirá na sua vida profissional e facilitará sua comunicação com pessoas surdas e usuários da língua de sinais. Dentre os pesquisados, a expressiva maioria (94.4\%) tem interesse de prosseguir em praticar/estudar Libras. É verdade que o processo de aquisição de uma nova língua requer disciplina e esforço, e nem sempre é possível para alguns separar um tempo para estabelecer este alvo.

Mas, focando naqueles que se interessam, é desejo da coordenação do Projeto extensionista que visa difundir a Libras prosseguir com iniciativas assim. Toda a equipe do Projeto entende a relevância de qualquer esforço para sensibilizar ouvintes quanto à aprendizagem de Libras. É preciso firmar na consciência de cada integrante de um curso de Libras que este aprendizado deverá transcender a finalização do curso. Cada aluno(a) deverá prosseguir nos estudos desta língua visando expandir suas capacidades individuais ao mesmo tempo que terá mais condições de interagir com a comunidade surda, enriquecendo a si mesmo(a) como pessoa.

Foi digno de nota um comentário extraído da pesquisa: "Na minha opinião, deveria ter pelo menos uma matéria do básico de Libras nas escolas. [...] assim podemos nos comunicar sem nenhum problema e nem preconceito [...]"

Seria, de fato, muito válido para toda a sociedade uma mobilização bem articulada para que tal realidade se concretizasse. Hoje, as escolas não são inclusivas, muito menos bilíngues. De acordo com Lacerda \& Mantelatto (2000):

\footnotetext{
“...o Bilinguismo visa à exposição da criança surda à língua de sinais o mais precocemente possível, pois esta aquisição propiciará ao surdo um desenvolvimento rico e pleno de linguagem e, consequentemente um desenvolvimento integral." (Lacerda \& Mantelatto, 2000. p. 21-41.)
}

Quanto mais cedo a pessoa surda tiver contato com a Libras, mais cedo ela se desenvolverá e terá a aquisição da segunda língua com mais praticidade. Acerca desse tema, Strobel (2008) afirma: 


\begin{abstract}
"A língua de sinais é uma das principais marcas da identidade de um povo surdo, pois é uma das peculiaridades da cultura surda, é uma forma de comunicação que capta as experiências visuais do sujeito surdo, e que vai levar o surdo a transmitir e proporcionar a aquisição de conhecimento universal." (Strobel, 2008. P. 53.)
\end{abstract}

Sacks (2010) defende que os surdos têm mais facilidade e maior precisão em se comunicar pela língua de sinais porque é por esse meio que o cérebro deles se adapta, e se são forçados a falar nunca conseguirão uma linguagem eficiente, tornando-os assim duplamente deficientes. Sem linguagem não somos seres humanos completos e, por isso, é inútil ir contra a natureza, sendo melhor aceita-la. Quando os surdos são obrigados a falar, algo que não lhes é natural, não exposto suficientemente à linguagem na qual melhor se manifestariam, eles terminam condenados ao isolamento e à incapacidade de formar sua identidade cultural (SACKS, 2010).

Um psiquiatra surdo norueguês Terje Basilier, citado por Brito (1993), diz a seguinte frase: [...] quando eu aceito a língua de outra pessoa, eu aceitei a pessoa [...]. Quando eu rejeito a língua, eu rejeitei a pessoa, porque a língua é parte de nós mesmos [...] Quando eu aceito a língua de sinais, eu aceito o surdo, e é importante ter sempre em mente que o surdo tem o direito de ser surdo. (FERREIRA BRITO, 1993 apud WITKOSKI,2009). Quando negamos a um povo a possibilidade de se comunicar em sua língua natural, negamos também o direito de vivenciar e de formar sua identidade cultural, pois a língua é uma das características mais forte de um povo. Quando aceitamos a língua de outra pessoa, na realidade a aceitamos sem reservas. E quando se rejeita a língua, se rejeita também o sujeito, pois a língua faz parte intrínseca de quem ele ou ela é.

Quando colocamos um limite na linguagem e na língua, colocamos um limite no mundo do outro, pois são a partir destes dois elementos que enxergamos o mundo, que o percebemos e que traçamos limites no nosso sentir e pensar. O mais importante meio de identificação do indivíduo com sua cultura é o suporte do conhecimento da realidade que nos circunda: se tiramos isso de alguém, de um surdo, arrancamos o direito de ele ser quem ele é, e tiramos dele uma parte significativa de sua identidade. 
Como integrante do Projeto Clube de Libras UFC, manifesto minha satisfação em integrar a equipe e já ter podido ter uma experiência prática no ensino e difusão da Libras e da cultura surda. Tenho plena certeza de que os esforços empreendidos para que esta língua se fortaleça e seja amplamente conhecida contribuirão para uma sociedade mais feliz, com integrantes mais aptos a compreenderem seu próximo. E esta compreensão mútua proporcionará a todos, ouvintes e surdos, uma convivência mais enriquecida de interações válidas e solidárias.

\section{REFERÊNCIAS}

IBGE. Deficiência: uma em cada cem pessoas tem deficiência física causada por doença ou acidente. Comunicação Social, em 21 ago. 2015. Disponível em:

$<$ https://censo2010.ibge.gov.br/noticias-censo.html?busca=1\&id=1\&idnoticia=2965\&t=pns2013-dois-anos-mais-metade-nascimentos-ocorreram-cesariana\&view=noticia>. Acesso em: 22 nov. 2020.

LACERDA, Cristina Broglia Feitosa de; MANTELATTO, Sueli Aparecida Caporali. As diferentes concepções de linguagem na prática fonoaudiológica junto a sujeitos surdos. In: LACERDA, C. B. F.; NAKAMURA, H.; LIMA, M. C. (Org.). Fonoaudiologia: surdez e abordagem bilíngue. São Paulo: Plexus, 2000. p. 21-41. Porto Alegre: Mediação, 2002.

SACKS, Oliver. Vendo vozes: uma viagem ao mundo dos surdos. São Paulo: Companhia das Letras, 2010.

SKLIAR, Carlos. A surdez: um olhar sobre as diferenças. Porto Alegre: Mediação, 1998. p. 15.

STROBEL, Karin. As imagens do outro sobre cultura surda. Florianópolis: Editora da UFSC, 2008.

TUA CARREIRA. 73 frases de trabalho para as mais diversas ocasiões. Atualizado em 8 abr. 2020. Disponível em: <https://www.tuacarreira.com/frases-de-trabalho/>. Acesso em: 22 nov. 2020.

VYGOTSKY, Lev Semyonovich. Formação social da mente. São Paulo: Martins Fontes, 1998.

WITKOSKI, Sílvia Andreis. Surdez e preconceito: a norma da fala e o mito da leitura da palavra falada. Revista Brasileira de Educação, v. 14, n. 42, set./dez. 2009. Disponível em: <https://www.scielo.br/pdf/rbedu/v14n42/v14n42a12.pdf>. Acesso em: 22 nov. 2020. 